\title{
Polymorphisms of the pbp5 gene and correlation with ampicillin resistance in Enterococcus faecium isolates of animal origin
}

\author{
Patricia Poeta, ${ }^{1,2,3}$ Daniela Costa, ${ }^{1,2}$ Gilberto Igrejas, ${ }^{4}$ Yolanda Sáenz, ${ }^{2}$ \\ Myriam Zarazaga, ${ }^{2}$ Jorge Rodrigues ${ }^{1,3}$ and Carmen Torres ${ }^{2}$ \\ ${ }^{1}$ Departamento de Ciências Veterinárias, Universidade de Trás-os-Montes e Alto Douro, Vila \\ Real, Portugal \\ ${ }^{2}$ Área de Bioquímica y Biología Molecular, Universidad de La Rioja, Logroño, Spain \\ ${ }^{3}$ Centro de Estudos de Ciências Animais e Veterinárias, Vila Real, Portugal \\ ${ }^{4}$ Departamento de Genética e Biotecnologia, Universidade de Trás-os-Montes e Alto Douro, \\ Vila Real, Portugal
}

Correspondence

Carmen Torres

carmen.torres@daa.unirioja.es

Received 12 June 2006

Accepted 5 October 2006

\begin{abstract}
The C-terminal region of the pbp5 gene was sequenced in 11 ampicillin-resistant and 5 ampicillin-susceptible Enterococcus faecium isolates of animal origin, and compared with a pbp5 reference sequence (GenBank accession no. X84860). Eight different $p b p 5$ alleles (designated A-H) were detected when amino acid changes in the region 461-629 were considered. Three of these alleles $(A-C)$ were detected in ampicillin-susceptible isolates (MIC range 1-8 $\mu \mathrm{g} \mathrm{ml}^{-1}$ ), and included the changes $470 \mathrm{H} \rightarrow \mathrm{Q}, 471 \mathrm{~V} \rightarrow \mathrm{I}, 487 \mathrm{Q} \rightarrow \mathrm{L}, 581 \mathrm{l} \rightarrow \mathrm{V}, 595 \mathrm{E} \rightarrow \mathrm{A}$ or $622 \mathrm{E} \rightarrow \mathrm{D}$. The remaining five alleles $(\mathrm{D}-\mathrm{H})$ were found in ampicillin-resistant isolates (MIC range 32-256 $\mathrm{g} \mathrm{m} \mathrm{m}^{-1}$ ); three of these alleles $(\mathrm{F}-\mathrm{H})$ presented a serine insertion at position 466', in addition to other important amino acid changes $(485 \mathrm{M} \rightarrow \mathrm{A}, 496 \mathrm{~N} \rightarrow \mathrm{K}, 499 \mathrm{~A} \rightarrow \mathrm{T}, 525 \mathrm{E} \rightarrow \mathrm{D}$, $586 \mathrm{~V} \rightarrow \mathrm{L}$ or $629 \mathrm{E} \rightarrow \mathrm{V}$ ). The other two alleles presented the amino acid changes $496 \mathrm{~N} \rightarrow \mathrm{K}$ and $629 \mathrm{E} \rightarrow \mathrm{V}$ (allele $\mathrm{D}$ ), and $470 \mathrm{H} \rightarrow \mathrm{Q}$ (allele F). A correlation between deduced amino acid changes in PBP5 and ampicillin MICs was detected in animal E. faecium isolates.
\end{abstract}

\section{INTRODUCTION}

Enterococcus faecium is an important human pathogen whilst also being a commensal bacterium of the intestinal tract of humans and animals. E. faecium is intrinsically resistant to moderate levels of ampicillin, with MICs typically ranging from 1 to $16 \mu \mathrm{g} \mathrm{ml}^{-1}$ (Kak \& Chow, 2002). This natural ampicillin resistance of E. faecium was demonstrated to be associated with expression of penicillinbinding protein 5 (PBP5), which has a low affinity for $\beta$ lactams (Fontana et al., 1983, 1994; Rice et al., 2001). The pbp5 gene is located in the bacterial chromosome and is considered to be intrinsic to the species, although recently it has also been reported as a transferable determinant (Rice et al., 2005). Recently, an increase in ampicillin resistance has been observed in clinical E. faecium isolates, which could compromise therapy in life-threatening infections caused by this micro-organism (Klare et al., 2003). The emergence of high-level ampicillin resistance in E. faecium may be due to either increased production of PBP5 or mutations in the pbp5 gene resulting in lower affinities for ampicillin (Kak \& Chow, 2002; Rice et al., 2001; Sifaoui et al., 2001; Williamson

Abbreviation: PBP5, penicillin-binding protein 5. et al., 1983; Zorzi et al., 1996). Specific amino acid changes in the C-terminal region of PBP5 (especially at aa 466', 485, $496,499,525,586$ and 629 , around the active-site region of PBP5) have been associated with $\beta$-lactam resistance (Jureen et al., 2003; Ligozzi et al., 1996; Rice et al., 2001, 2004; Rybkine et al., 1998; Sauvage et al., 2002; Zorzi et al., 1996), and 12 different alleles of this gene have previously been demonstrated in clinical E. faecium isolates when this Cterminal region of $p b p 5$ gene was analysed (Jureen et al., 2003).

As far as we know, all studies of the characterization and detection of mutations in $p b p 5$ have been performed on $E$. faecium isolates of human origin and not on animal isolates. Thus, the $p b p 5$ gene of ampicillin-resistant $\left(A m p^{\mathrm{R}}\right)$ and ampicillin-susceptible $\left(\mathrm{Amp}^{\mathrm{S}}\right)$ E. faecium isolates recovered from healthy animals was sequenced in the present study. The deduced amino acid changes were found to correlate with their specific ampicillin MICs.

\section{METHODS}

Bacterial isolates. Antimicrobial resistance was analysed by the disc-diffusion method in a previous study in enterococcal isolates 
recovered from faecal samples of healthy poultry and pets (Poeta et al., 2006). A total of $11 \mathrm{E}$. faecium isolates of that study showed an $A m p^{R}$ phenotype, comprising 10 faecal samples from poultry and 1 faecal sample from a dog. These $11 \mathrm{Amp}^{\mathrm{R}}$ E. faecium isolates, as well as $5 \mathrm{Amp}^{\mathrm{S}}$ E. faecium isolates (4 from poultry and 1 from a dog), were included in the present study.

Ampicillin-susceptibility testing. The MIC of ampicillin (Eli Lilly) was determined in our E. faecium isolates using the agar-dilution method according to the Clinical and Laboratory Standards Institute (formerly the National Committee for Clinical Laboratory Standards, 2005). Enterococcus faecalis ATCC 29212 and Staphylococcus aureus ATCC 25923 were used as quality-control strains.

Analysis of $\boldsymbol{\beta}$-lactamase activity. The production of $\beta$-lactamase was tested by streaking the bacterial colonies over nitrocefin discs (Cefinase; Becton Dickinson Microbiology Systems) (Marshall et al., 1995). After 5-10 min at room temperature, a change in colour from yellow to purple was indicative of a positive reaction.

PCR amplification of pbp5 and DNA sequence analysis. Total DNA from E. faecium isolates was obtained using an InstaGene matrix (Bio-Rad) and $10 \mu \mathrm{l}$ DNA was used in each PCR, with $3.5 \mathrm{mM} \mathrm{MgCl}$. The C-terminal region of the $p b p 5$ gene was amplified by PCR in all 16 E. faecium isolates included in this study using primers PBP5F-1 (5'-AACAAAATGACAAACGGG-3') and PBP5R (5'-TATCCTTGGTTATCAGGG-3'), producing an amplicon of $779 \mathrm{bp}$. PCR conditions were as follows: $95^{\circ} \mathrm{C}$ for $5 \mathrm{~min}$, followed by 30 cycles of $94{ }^{\circ} \mathrm{C}$ for $30 \mathrm{~s}, 54{ }^{\circ} \mathrm{C}$ for $30 \mathrm{~s}$ and $72{ }^{\circ} \mathrm{C}$ for $2 \mathrm{~min}$, with a final $7 \mathrm{~min}$ extension period at $72^{\circ} \mathrm{C}$ (Jureen et al., 2003). PCR products were detected on ethidium-bromide-stained agarose gels and purified using a QIAquick gel extraction kit (Qiagen), according to the manufacturer's instructions. The purified products were sequenced on both strands using an Applied Biosystems 3730 DNA sequencer, using primers PBP5F-2 (5'GACAAACGGGATCTCACAAG-3') and PBP5R. Duplicated sequences were obtained from independent PCRs and compared with that of the $p b p 5$ gene reference sequence (GenBank accession no. X84860).

The complete $p b p 5$ gene was also amplified by PCR in six of our $E$. faecium isolates (two $\mathrm{Amp}^{\mathrm{S}}$ and four $\mathrm{Amp}^{\mathrm{R}}$ ) using primers PBP5F-3 (5'-AAAAATCGAACAACAGGCGCTTA-3') and PBP5R (amplicon size $1916 \mathrm{bp}$ ), using TaKaRa DNA polymerase (Takara Bio) under conditions recommended by the manufacturer. Amplicons were purified and sequenced by primer walking. The sequences obtained from both strands were also compared with that of the reference sequence.

\section{RESULTS AND DISCUSSION}

Polymorphisms of the $p b p 5$ gene were studied in a series of E. faecium isolates of animal origin that showed different susceptibilities to ampicillin. None showed $\beta$-lactamase activity when nitrocefin discs were used for screening purposes.

\section{C-terminal region of the pbp5 gene}

The sequence of the C-terminal region of $p b p 5$ was analysed in our $11 \mathrm{Amp}^{\mathrm{R}}$ and $5 \mathrm{Amp}^{\mathrm{S}}$ E. faecium isolates and was correlated with their specific ampicillin MIC values. The deduced amino acid changes detected between aa 461 and 634 of these enterococci are shown in Table 1, with amino acid positions considered to be important for ampicillin resistance indicated in bold.
Eight different $p b p 5$ alleles, designated here as $\mathrm{A}-\mathrm{H}$, were detected when amino acid changes in this region were taken into account, none of which showed $100 \%$ identity with the reference sequence (GenBank accession no. X84860). Our five $\mathrm{Amp}^{\mathrm{S}}$ isolates (MICs $1-8 \mu \mathrm{g} \mathrm{ml}^{-1}$ ) were classified as only three of these alleles $(\mathrm{A}-\mathrm{C})$ and included changes at positions not previously considered to be important for ampicillin resistance (allele A $470 \mathrm{H} \rightarrow \mathrm{Q}, 581 \mathrm{I} \rightarrow \mathrm{V}, 595 \mathrm{E} \rightarrow \mathrm{A}$; allele B $470 \mathrm{H} \rightarrow \mathrm{Q}, 595 \mathrm{E} \rightarrow \mathrm{A}$; allele $\mathrm{C} 470 \mathrm{H} \rightarrow \mathrm{Q}, 471 \mathrm{~V} \rightarrow \mathrm{I}$, $487 \mathrm{Q} \rightarrow \mathrm{L}, 622 \mathrm{E} \rightarrow \mathrm{D})($ Table 1$)$. The remaining five alleles $(\mathrm{D}-\mathrm{H})$ were found in our $11 \mathrm{Amp}^{\mathrm{R}}$ isolates. It is important to stress that three of these alleles $(\mathrm{F}-\mathrm{H})$ presented a serine insertion at position $466^{\prime}$ in addition to other important amino acid changes: alleles $\mathrm{F}$ and $\mathrm{H}(485 \mathrm{M} \rightarrow \mathrm{A}, 496 \mathrm{~N} \rightarrow \mathrm{K}$, $499 \mathrm{~A} \rightarrow \mathrm{T}, 525 \mathrm{E} \rightarrow \mathrm{D}$ and $629 \mathrm{E} \rightarrow \mathrm{V})$ and allele $\mathrm{G}(485 \mathrm{M} \rightarrow \mathrm{A}$, $496 \mathrm{~N} \rightarrow \mathrm{K}, 499 \mathrm{~A} \rightarrow \mathrm{T}, 525 \mathrm{E} \rightarrow \mathrm{D}, 586 \mathrm{~V} \rightarrow \mathrm{L}$ and $629 \mathrm{E} \rightarrow \mathrm{V})$. Allele $\mathrm{F}$, identified in seven $\mathrm{Amp}^{\mathrm{R}}$ isolates (MICs 32-256 $\mu \mathrm{g} \mathrm{ml}^{-1}$ ), was the most frequent allele in our study. Allele D was found in one $\mathrm{Amp}^{\mathrm{R}}$ isolate (MIC $32 \mu \mathrm{g} \mathrm{ml}^{-1}$ ) and showed amino acid changes at two principal positions $(496 \mathrm{~N} \rightarrow \mathrm{K}$ and $629 \mathrm{E} \rightarrow \mathrm{V})$. The remaining allele (E) was detected in one $A m p^{R}$ isolate (MIC $64 \mu \mathrm{g} \mathrm{ml}^{-1}$ ), recovered from a dog, and showed only one amino acid change $(470 \mathrm{H} \rightarrow \mathrm{Q})$ with respect to the reference sequence. This specific substitution was also found in all of our isolates, both $A \mathrm{mp}^{\mathrm{R}}$ and $\mathrm{Amp} \mathrm{p}^{\mathrm{S}}$, and has not previously been associated with increased ampicillin MICs by other authors (Jureen et al., 2003).

It is important to note that the insertion of serine at position $466^{\prime}$ was detected in most of our $\mathrm{Amp}^{\mathrm{R}}$ animal E. faecium isolates, and was generally associated with other amino acid changes. Insertions of aspartic acid or serine at position 466' have also been detected previously in strains with an increased level of ampicillin resistance (Jureen et al., 2003; Rybkine et al., 1998; Zorzi et al., 1996). According to the previously reported PBP5 crystal structure (Sauvage et al., 2002), when PBP5 protein of E. faecium (PBP5fm) forms a complex with benzylpenicillin, the active-site cavity of this protein is delimited by the $\beta_{\mathrm{C} 3}$ strand on one side, by residues 461-465 on the opposite side and by residues 537-541 on the bottom of the cavity. Residues 461-465 form part of a loop (aa 451-465) that is well conserved in the B1 subgroup of class B high-molecular-mass PBPs. Thus, the substitution $461 \mathrm{Q} \rightarrow \mathrm{K}$ found in most of our $\mathrm{Amp}^{\mathrm{R}}$ strains could be implicated in lower affinity for the antibiotic. The residue V465 points into the active site, being close to the $\beta$ lactam ring; therefore, the insertion of a residue at position 466' may slightly displace V465 inside the active site, reducing its accessibility for ampicillin (Rice et al., 2004; Sauvage et al., 2002). The serine insertion was found in the strains with high-level ampicillin resistance and seems to be an essential determinant of resistance, affecting antibiotic recognition.

As in the findings of other authors (Rybkine et al., 1998; Zorzi et al., 1996), the change of methionine to alanine at aa 485 was observed in isolates with higher MICs 
Table 1. Polymorphisms in the C-terminal region of pbp5 in 16 E. faecium isolates of animal origin and correlation with their specific ampicillin MIC values

\begin{tabular}{|c|c|c|c|c|c|c|c|c|c|c|c|c|c|c|c|c|c|}
\hline \multirow{2}{*}{$\begin{array}{l}\text { E. faecium } \\
\text { isolate }\end{array}$} & \multirow{2}{*}{$\begin{array}{c}p b p 5 \\
\text { allele }^{*}\end{array}$} & \multicolumn{15}{|c|}{ Amino acid change at position: $\dagger$} & \multirow{2}{*}{$\begin{array}{c}\text { Ampicillin } \\
\operatorname{MIC}\left(\mu \mathrm{g} \mathrm{ml}^{-1}\right)\end{array}$} \\
\hline & & 461 & $466^{\prime}$ & 470 & 471 & 485 & 487 & 496 & 497 & 499 & 525 & 581 & 586 & 595 & 622 & 629 & \\
\hline X84860 & & Q & - & $\mathrm{H}$ & $\mathrm{V}$ & M & Q & $\mathrm{N}$ & $\mathrm{F}$ & A & E & I & V & $\mathrm{E}$ & $\mathrm{E}$ & $\mathrm{E}$ & \\
\hline $\mathrm{P} 4$ & A & Q & - & $\mathbf{Q}$ & $\mathrm{V}$ & M & Q & $\mathrm{N}$ & $\mathrm{F}$ & A & E & $\mathbf{V}$ & $\mathrm{V}$ & A & $\mathrm{E}$ & $\mathrm{E}$ & 1 \\
\hline P44 & B & Q & - & Q & $\mathrm{V}$ & M & Q & $\mathrm{N}$ & $\mathrm{F}$ & A & E & I & V & A & $\mathrm{E}$ & E & 4 \\
\hline P47 & B & Q & - & $\mathbf{Q}$ & V & $\mathrm{M}$ & Q & $\mathrm{N}$ & $\mathrm{F}$ & A & E & I & $\mathrm{V}$ & A & $\mathrm{E}$ & E & 4 \\
\hline $\mathrm{P} 43$ & B & Q & - & $\mathbf{Q}$ & $\mathrm{V}$ & $\mathrm{M}$ & $\mathrm{Q}$ & $\mathrm{N}$ & $\mathrm{F}$ & A & E & I & V & A & $\mathrm{E}$ & $\mathrm{E}$ & 8 \\
\hline P54 & C & Q & - & Q & I & $\mathrm{M}$ & $\mathbf{L}$ & $\mathrm{N}$ & $\mathrm{F}$ & A & E & I & V & $\mathrm{E}$ & D & $\mathrm{E}$ & 4 \\
\hline P12 & $\mathrm{D}$ & Q & - & $\mathbf{Q}$ & V & $\mathrm{M}$ & Q & $\mathbf{K}$ & F & A & E & I & V & E & $\mathrm{E}$ & V & 32 \\
\hline P $42 \ddagger$ & $\mathrm{E}$ & Q & - & Q & $\mathrm{V}$ & $\mathrm{M}$ & $\mathrm{Q}$ & $\mathrm{N}$ & $\mathrm{F}$ & A & $\mathrm{E}$ & I & V & $\mathrm{E}$ & $\mathrm{E}$ & $\mathrm{E}$ & 64 \\
\hline P67 & F & $\mathbf{K}$ & $S$ & $\mathbf{Q}$ & $\mathrm{V}$ & A & Q & $\mathbf{K}$ & F & $\mathbf{T}$ & D & I & V & E & E & V & 32 \\
\hline P76 & F & $\mathbf{K}$ & $S$ & $\mathbf{Q}$ & V & A & Q & $\mathbf{K}$ & F & $\mathbf{T}$ & D & I & V & $\mathrm{E}$ & $\mathrm{E}$ & V & 32 \\
\hline P13 & $\mathrm{F}$ & $\mathbf{K}$ & $S$ & $\mathbf{Q}$ & $\mathrm{V}$ & A & $\mathrm{Q}$ & $\mathbf{K}$ & $\mathrm{F}$ & $\mathbf{T}$ & D & I & $\mathrm{V}$ & E & E & V & 128 \\
\hline $\mathrm{P} 1$ & F & $\mathbf{K}$ & $S$ & $\mathbf{Q}$ & $\mathrm{V}$ & A & Q & $\mathbf{K}$ & $\mathrm{F}$ & $\mathbf{T}$ & D & I & $\mathrm{V}$ & E & E & V & 256 \\
\hline P3 & F & $\mathbf{K}$ & $S$ & $\mathbf{Q}$ & $\mathrm{V}$ & A & Q & $\mathbf{K}$ & $\mathrm{F}$ & $\mathbf{T}$ & D & I & $\mathrm{V}$ & $\mathrm{E}$ & $\mathrm{E}$ & V & 256 \\
\hline $\mathrm{P} 4$ & $\mathrm{~F}$ & $\mathbf{K}$ & $S$ & Q & $\mathrm{V}$ & A & $\mathrm{Q}$ & $\mathbf{K}$ & $\mathrm{F}$ & $\mathbf{T}$ & D & I & $\mathrm{V}$ & $\mathrm{E}$ & $\mathrm{E}$ & $\mathbf{V}$ & 256 \\
\hline P6 & $\mathrm{F}$ & $\mathbf{K}$ & $S$ & $\mathbf{Q}$ & V & A & Q & $\mathbf{K}$ & $\mathrm{F}$ & $\mathbf{T}$ & D & I & V & $\mathrm{E}$ & $\mathrm{E}$ & V & 256 \\
\hline $\mathrm{P} 2$ & G & $\mathbf{K}$ & $S$ & $\mathbf{Q}$ & $\mathrm{V}$ & A & Q & $\mathbf{K}$ & F & $\mathrm{T}$ & D & I & $\mathbf{L}$ & $\mathrm{E}$ & $\mathrm{E}$ & V & 128 \\
\hline P11 & $\mathrm{H}$ & $\mathbf{K}$ & $S$ & $\mathbf{Q}$ & $\mathrm{V}$ & A & $\mathrm{Q}$ & $\mathbf{K}$ & $\mathbf{L}$ & $\mathbf{T}$ & D & I & $\mathrm{V}$ & E & E & $\mathbf{V}$ & 256 \\
\hline
\end{tabular}

*Alleles were designated A-H based on amino acid substitutions.

$\dagger$ Important amino acid positions and amino acid changes with respect to the reference sequence (GenBank accession no. X84860) are indicated in bold.

¥Allele E, detected in the $p b p 5$ gene of the P42 isolate, was equivalent to allele 3 described by Jureen et al. (2003).

(128-256 $\left.\mu \mathrm{g} \mathrm{ml}^{-1}\right)$, although two isolates showed a MIC of $32 \mu \mathrm{g} \mathrm{ml}^{-1}$. The bulky side chain of M485 located behind the K425 side chain is substituted by the small alanine molecule, obtaining more conformational space for lysine and resulting in a lower affinity for the $\beta$-lactam antibiotic. Although the substitution $485 \mathrm{M} \rightarrow \mathrm{A}$ seems to be important for ampicillin resistance, it has been reported that this change by itself does not confer high-level ampicillin resistance (Sifaoui et al., 2001), as observed in our study.

We identified only one $\mathrm{Amp}^{\mathrm{R}}$ isolate (MIC $128 \mu \mathrm{g} \mathrm{ml}^{-1}$ ) that showed the $586 \mathrm{~V} \rightarrow \mathrm{L}$ substitution. However, Ligozzi et al. (1996) suggested that the region from aa 558 to 586 might play an important role in the $\beta$-lactam-binding site of PBP5, as changes in this region occurred in the highly resistant strains. Residue 629 is close to one edge of the active site and the $629 \mathrm{E} \rightarrow \mathrm{V}$ substitution causes a change of a hydrophilic charged residue for a hydrophobic one, which is unfavourable for the overall stability of the protein and may decrease the ability of the protein to bind to $\beta$-lactam by restricting mobility (Leszczynski \& Rose, 1986; Rice et al., 2004).

In a comparison of the 8 alleles of the $p b p 5$ gene detected in our animal isolates with the 12 alleles reported by Jureen $e t$ al. (2003) in human isolates, it is important to note that only one of our alleles (allele E with the single change $470 \mathrm{H} \rightarrow \mathrm{Q}$ ) corresponded to one of those determined by Jureen and coworkers (designated allele 3 ). Allele 3 of $p b p 5$ was detected particularly among $\mathrm{Amp}^{\mathrm{S}}$ human isolates and also in a few $\mathrm{Amp}^{\mathrm{R}}$ isolates (Jureen et al., 2003). In our study, allele $\mathrm{E}$ was found in one $A_{m p}{ }^{R}$ E. faecium isolate (P42, MIC $64 \mu \mathrm{g} \mathrm{ml}^{-1}$ ) recovered from a dog faecal sample.

If only the potentially significant amino acid positions (466', $485,496,499,525,586$ and 629) of the C-terminal region of PBP5 were considered, all of our $\mathrm{Amp}^{\mathrm{S}}$ isolates presented the same amino acid pattern as the reference sequence. In the case of $A m p^{R}$ isolates, four different patterns could be identified: (i) amino acid changes at the above seven positions in one isolate (MIC $128 \mu \mathrm{g} \mathrm{ml}^{-1}$, allele G); (ii) changes at six positions in eight isolates (MICs 32-256 $\mu \mathrm{g} \mathrm{ml}^{-1}$, alleles $\mathrm{F}$ and $\mathrm{H}$ ); (iii) changes at two positions in one isolate (MIC $32 \mu \mathrm{g} \mathrm{ml}^{-1}$, allele D); and (iv) no changes at important positions in one isolate ( $\mathrm{P} 42$, MIC $64 \mu \mathrm{g} \mathrm{ml}^{-1}$, allele E) (Table 1). Thus, it seems that specific alterations in the C-terminal part of the $p b p 5$ gene alone could not entirely be correlated with the different levels of ampicillin resistance among our strains and other factors are probably implicated (Jureen et al., 2004; Rice et al., 2001; Sifaoui et al., 2001).

\section{$\mathrm{N}$-terminal region of the pbp5 gene}

In order to determine whether the ampicillin resistance phenotype detected in E. faecium P42 (allele E) was due to amino acid changes in positions outside the C-terminal 
region of $p b p 5$, the complete $p b p 5$ gene was amplified and sequenced for this isolate, as well as for five additional $\mathrm{Amp}^{\mathrm{R}}$ and Amp ${ }^{S}$ E. faecium isolates (P44, P54, P13, P2 and P11, belonging to alleles $\mathrm{B}, \mathrm{C}, \mathrm{F}, \mathrm{G}$ and $\mathrm{H}$, respectively). The amino acid changes detected in the $\mathrm{N}$-terminal region of the $p b p 5$ gene of these isolates with respect to the reference sequence are indicated in Table 2 . It was found that $E$. faecium $\mathrm{P} 42$ and one of the $\mathrm{Amp}^{\mathrm{S}}$ isolates showed no amino acid changes with respect to the reference sequence, whilst four changes were detected in the other Amps isolate. Nevertheless, a large number (up to 12) and variety of amino acid changes were demonstrated in this region in the three $\mathrm{Amp}^{\mathrm{R}}$ isolates (P2, P11 and P13). Zorzi et al. (1996) described most of these amino acid changes in the $\mathrm{N}$ terminal domain of their studied strains, with the $68 \mathrm{~A} \rightarrow \mathrm{T}$ and $85 \mathrm{E} \rightarrow \mathrm{D}$ substitutions only detected in the highly resistant penicillin strains (EFM-1 and H80721, with MICs of 90 and $512 \mu \mathrm{g} \mathrm{ml}^{-1}$, respectively). These two changes were also observed in our high-level $A m p^{R}$ isolates. The function of the $\mathrm{N}$-terminal domain is still unclear. It has been hypothesized that it is necessary for correct folding of the Cterminal module and both domains seem to be interdependent (Sauvage et al., 2002). In fact, deletion of some segments of the N-terminal domain of PBP5 from Enterococcus hirae resulted in proteins that were unable to bind penicillin (Mollerach et al., 1996). Future studies should be carried out to determine whether the amino acid changes in the $\mathrm{N}$ terminal region of PBP5 could be associated with changes in $\beta$-lactam susceptibility in E. faecium species.

\section{Conclusions}

The specific alterations in the C-terminal part of the $p b p 5$ gene could be used as markers for ampicillin resistance (at least the insertion at aa $466^{\prime}$ and the changes at position 485), as they are present in most of the $A m p^{R}$ but not in the $\mathrm{Amp}^{\mathrm{S}}$ strains, although, as observed by other researchers (Jureen et al., 2004; Rice et al., 2001; Sifaoui et al., 2001), it seems that other factors could be necessary for a complete explanation of the differences in levels of ampicillin resistance. High levels of resistance could be observed in strains that either overexpress $\mathrm{PBP} 5$ and/or present multiple mutations that decrease the affinity of PBP5 for the antibiotic. This possibility could explain the different levels of ampicillin resistance among strains classified as the same allele (allele F) or the P42 strains whose MIC values could be due simply to protein overexpression. Zorzi et al. (1996) suggested that only a single copy of the $p b p 5$ gene was present in their analysed strains. Thus, the variations seen in the amount of PBP5 could not be due to a gene dosage effect, although the detection of $p b p 5$ located within transferable elements could change this suggestion (Rice et al., 2005). More recently, it has been reported that expression of ampicillin resistance was higher when the $p b p 5$ gene was located downstream of the $f t s W_{\mathrm{Efm}}$ and $p s r$ genes (Rice et al., 2001). The role of the putative $f t s W_{\mathrm{Efm}}$ gene product is unknown, although it has been suggested that its homologue in Escherichia coli may serve as a chaperone protein for PBP3 (Eberhardt et al., 2003). In addition, it has been proposed that overproduction of PBP5 could result from either an alteration in the $p s r$ promoter or a modification of the target site of Psr, probably located between the $p s r$ and $p b p 5$ genes (Zorzi et al., 1996).

In conclusion, the C-terminal region of the $p b p 5$ gene was found to be highly polymorphic among our $A m p^{R}$ and $\mathrm{Amp}^{\mathrm{S}}$ E. faecium isolates of animal origin and there seemed to be a correlation between specific changes located at positions close to the active site of PBP5 and the ampicillin MIC, although further studies of the mechanisms of ampicillin resistance in E. faecium are necessary.

\section{ACKNOWLEDGEMENTS}

P. P. was supported by a grant with the reference SFRH/BD/17424/2004 from Fundaçao para a Ciência e a Tecnologia (FCT) of Portugal. This work has been financed in part by the Integrated Action SpainPortugal from the Ministry of Education and Science (HP2005-0052).

Table 2. Amino acid changes detected in the N-terminal region of $p b p 5$ in six of the $E$. faecium isolates of this study

\begin{tabular}{|c|c|c|c|c|c|c|c|c|c|c|c|c|c|c|}
\hline $\begin{array}{l}E . \\
\text { faecium }\end{array}$ & \multicolumn{13}{|c|}{ Amino acid change at position:* } & $\begin{array}{c}\text { Ampicillin } \\
\text { MIC }\left(\mu \mathrm{g} \mathrm{ml}^{-1}\right.\end{array}$ \\
\hline $\mathrm{P} 44$ & $S$ & $\mathrm{R}$ & G & A & A & $\mathrm{E}$ & $\mathrm{E}$ & K & $\mathrm{T}$ & $\mathrm{L}$ & $\mathrm{D}$ & A & $\mathrm{T}$ & 4 \\
\hline P54 & G & $\mathrm{R}$ & G & $\mathrm{A}$ & $\mathbf{T}$ & $\mathrm{E}$ & $\mathrm{E}$ & $\mathbf{Q}$ & $\mathrm{T}$ & $\mathrm{L}$ & $\mathrm{D}$ & A & $\mathbf{A}$ & 4 \\
\hline P42 & $S$ & $\mathrm{R}$ & G & A & A & $\mathrm{E}$ & $\mathrm{E}$ & K & $\mathrm{T}$ & $\mathrm{L}$ & $\mathrm{D}$ & A & $\mathrm{T}$ & 64 \\
\hline P11 & G & $\mathbf{Q}$ & $\mathbf{E}$ & $\mathbf{T}$ & A & D & $\mathbf{Q}$ & $\mathbf{Q}$ & A & I & G & $S$ & $\mathbf{A}$ & 256 \\
\hline
\end{tabular}

NA, The sequence at this position was not available.

${ }^{\star}$ Amino acid changes with respect to the reference sequence (GenBank accession no. X84860) are indicated in bold. 


\section{REFERENCES}

Eberhardt, C., Kuerschner, L. \& Weiss, D. S. (2003). Probing the catalytic activity of a cell division-specific transpeptidase in vivo with $\beta$-lactams. J Bacteriol 185, 3726-3734.

Fontana, R., Cerini, R., Longoni, P., Grossato, A. \& Canepari, P. (1983). Identification of a streptococcal penicillin-binding protein that reacts very slowly with penicillin. J Bacteriol 155, 1343-1350.

Fontana, R., Aldegheri, M., Ligozzi, M., Lopez, H., Sucari, A. \& Satta, G. (1994). Overproduction of a low-affinity penicillin-binding protein and high-level ampicillin resistance in Enterococcus faecium. Antimicrob Agents Chemother 38, 1980-1983.

Jureen, R., Top, J., Mohn, S. C., Harthug, S., Langeland, N. \& Willems, R. J. (2003). Molecular characterization of ampicillinresistant Enterococcus faecium isolates from hospitalized patients in Norway. J Clin Microbiol 41, 2330-2336.

Jureen, R., Mohn, S. C., Harthug, S., Haarr, L. \& Langeland, N. (2004). Role of penicillin-binding protein 5 C-terminal amino acid substitutions in conferring ampicillin resistance in Norwegian clinical strains of Enterococcus faecium. APMIS 112, 291-298.

Kak, V. \& Chow, J. W. (2002). Acquired antibiotic resistances in enterococci. In The Enterococci; Pathogenesis, Molecular Biology and Antibiotic Resistance, pp. 355-357. Washington, DC: American Society for Microbiology.

Klare, I., Konstabel, C., Badstübner, D., Werner, G. \& Witte, W. (2003). Occurrence and spread of antibiotic resistances in Enterococcus faecium. Int J Food Microbiol 88, 269-290.

Leszczynski, J. F. \& Rose, G. D. (1986). Loops in globular proteins: a novel category of secondary structure. Science 234, 849-855.

Ligozzi, M., Pittaluga, F. \& Fontana, R. (1996). Modification of penicillin-binding protein 5 associated with high-level ampicillin resistance in Enterococcus faecium. Antimicrob Agents Chemother 40, 354-357.

Marshall, S. A., Sutton, L. D. \& Jones, R. N. (1995). Evaluation of S1 chromogenic cephalosporin $\beta$-lactamase disk assay tested against Gram-positive anaerobes, coagulase-negative staphylococci, Prevotella spp. and Enterococcus spp. Diagn Microbiol Infect Dis 22, 353-355.

Mollerach, M. E., Partoune, P., Coyette, J. \& Ghuysen, J. M. (1996). Importance of the E-46-D-160 polypeptide segment of the nonpenicillin-binding module for the folding of the low-affinity, multimodular class B penicillin-binding protein 5 of Enterococcus hirae. J Bacteriol 178, 1774-1775.

National Committee for Clinical Laboratory Standards (2005). Performance Standards for Antimicrobial Susceptibility Testing, 15th informational supplement M100-S15. Wayne, PA: National Committee for Clinical Laboratory Standards.

Poeta, P., Costa, D., Rodrigues, J. \& Torres, C. (2006). Antimicrobial resistance and the mechanisms implicated in faecal enterococci from healthy humans, poultry and pets in Portugal. Int J Antimicrob Agents 27, 131-137.

Rice, L. B., Carias, L. L., Hutton-Thomas, R., Sifaoui, F., Gutmann, L. \& Rudin, S. D. (2001). Penicillin-binding protein 5 and expression of ampicillin resistance in Enterococcus faecium. Antimicrob Agents Chemother 45, 1480-1486.

Rice, L. B., Bellais, S., Carias, L., Hutton-Thomas, R., Bonomo, R. A., Caspers, P., Page, M. G. P. \& Gutmann, L. (2004). Impact of specific $p b p 5$ mutations on expression of $\beta$-lactam resistance in Enterococcus faecium. Antimicrob Agents Chemother 48, 3028-3032.

Rice, L. B., Carias, L. L., Rudin, S., Lakticová, V., Wood, A. \& HuttonThomas, R. (2005). Enterococcus faecium low-affinity $p b p 5$ is a transferable determinant. Antimicrob Agents Chemother 49, 5007-5012.

Rybkine, T., Mainardi, J. L., Sougakoff, W., Collatz, E. \& Gutmann, L. (1998). Penicillin-binding protein 5 sequence alterations in clinical isolates of Enterococcus faecium with different levels of $\beta$-lactam resistance. J Infect Dis 178, 159-163.

Sauvage, E., Kerff, F., Fonze, E., Herman, R., Schoot, B., Marquette, J. P., Taburet, Y., Prevost, D., Dumas, J. \& other authors (2002). The $2.4-\AA$ crystal structure of the penicillin-resistant penicillin-binding protein PBP5fm from Enterococcus faecium in complex with benzylpenicillin. Cell Mol Life Sci 59, 1223-1232.

Sifaoui, F., Arthur, M., Rice, L. \& Gutmann, L. (2001). Role of penicillin-binding protein 5 in expression of ampicillin resistance and peptidoglycan structure in Enterococcus faecium. Antimicrob Agents Chemother 45, 2594-2597.

Williamson, R., Calderwood, S. B., Moellering, R. C., Jr \& Tomasz, A (1983). Studies on the mechanism of intrinsic resistance to $\beta$-lactam antibiotic in group D streptococci. J Gen Microbiol 129, 813-822.

Zorzi, W., Zhou, X. Y., Dardenne, O., Lamotte, J., Raze, D., Pierre, J., Gutmann, L. \& Coyette, J. (1996). Structure of the low-affinity penicillin-binding protein 5 PBP5fm in wild-type and highly penicillin-resistant strains of Enterococcus faecium. J Bacteriol 178, 4948-4957. 